\title{
Comparative Tests of Shear Strength of Adhesive Lap Joints After Thermal Shocks
}

\author{
Mariusz Kłonica ${ }^{1 *}$, Radosław Bielawski², Mariusz Żokowski ${ }^{3}$ \\ 1 Faculty of Mechanical Engineering, Department of Production Engineering, Lublin University of Technology, \\ ul. Nadbystrzycka 36, 20-618 Lublin, Poland \\ 2 Faculty of Power and Aeronautical Engineering, Warsaw University of Technology, ul. Nowowiejska 24, 00- \\ 665 Warsaw, Poland \\ 3 Air Force Institute of Technology, ul. Księcia Bolesława 6, 01-494 Warsaw, Poland \\ *Corresponding author's e-mail:m.klonica@pollub.pl
}

\begin{abstract}
This work presents the results of comparative tests for the determination of Young's modulus and the static shear strength of adhesive lap joints, based on grade $316 \mathrm{~L}$ steel. The tests also concerned the determination of the glass transition temperature of a certain adhesive composition: Epidian 57 epoxy resin with a $10 \% \mathrm{Z} 1$ hardener content. The paper shows the test results for the surface free energy and selected surface roughness parameters, including photographs of the test specimens after destructive testing. The tests were comparative and performed on adhesive joints, with and without exposure to thermal cycling. The scope of the testing included a relatively short thermal cycling run of 500 cycles with a temperature variation of $-40^{\circ} \mathrm{C}$ to $+60^{\circ} \mathrm{C}$. An analysis was carried out of the results from testing the static shear resistance of specimens manufactured using various methods of adhesive joint seasoning. The experimental test results were statistically processed in compliance with good research practice.
\end{abstract}

Keywords: thermal cycling, adhesive joint, surface layer, surface roughness, 316L steel

\section{INTRODUCTION}

Adhesive compositions based on epoxy resins are one of the most popular materials used in adhesive processes. Adhesive joints are frequently used in many modern sectors of industry, especially in aerospace, automotive, and machine engineering. Adhesives and adhesive processes are utilised not only for bonding components of machines, but also to seal and encapsulate mechanical constructions. This is related to the many advantages provided by adhesives and adhesive joints. How good the adhesive bond is depends largely on the process of pretreating the faces of the materials to be joined [1-3]. As a rule of thumb, the adhesive processes are intended to "develop" the interface geometrically and provide an optimum energy state of the faces of the joined components $[1,4]$.
The design and process engineers decide when and how adhesive joints should be applied for operation under thermomechanical loads (or thermal shocks). The process of adhesive joint fatigue is an effect caused by stresses which change cyclically in time. This process results in a reduction of adhesive joint strength and durability, a consequence of which is structural failure at a stress lower than the static strength of the joint $[1,4]$. The issue of thermal fatigue in adhesive joints and its effects on long-term, reliable operation still remains an object of research [5-8].

Temperature significantly affects the strength of single adhesive lap joints. Changes in temperature by several to several dozen degrees Celsius which do not largely affect the properties of metals can change the properties of the long-chained plastics used as industrial adhesives. Varying thermal loads affect adhesive joints: first they introduce 
thermal stresses into the joint system and then they change the mechanical properties [9].

With the state of the art today it is possible to make hybrid joints by combining adhesive processes and traditional joining methods, like pressure welding or riveting [10-12].

The adhesive joint strength does not exceed the nominal tensile strength of the stainless steel given by the literature [13] and is far bellow the values of ultimate tensile strength reported for structural steels [14].

\section{EXPERIMENTAL PROCEDURE}

The tests were performed on an adhesive composition made of Epidian 57 epoxy resin with a $10 \% \mathrm{Z} 1$ hardener content. This material was used to manufacture the test specimens for the determination of the material properties. The general formula of the epoxy resin is shown in Figure 1.

The number $n$ depends on the type of epoxy resin and is characterised by the epoxy number. In the initial stage of curing between the amine group and the epoxy group, a hydroxyl group forms. A simplified diagram of this is shown with equation (1):

$\mathrm{RNH}_{2}+\underset{\mathrm{H}_{2} \mathrm{C}-\mathrm{O}-\mathrm{CH} m}{\mathrm{O}} \longrightarrow \mathrm{RNH}-\mathrm{CH}_{2}-\underset{\xi}{\mathrm{CH}}-\mathrm{OH}$

The product of the addition includes secondary amine groups which can react with the epoxy group of the next resin molecule in succession (2):

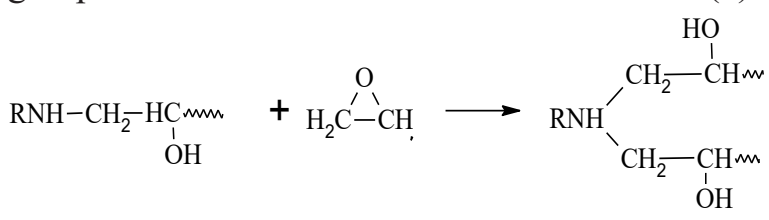

Some of the specimens were only seasoned at room temperature for seven days while the remainder were exposed to thermal shocks. These specimens were exposed to 500 thermal cycles (thermal shocks) in a thermal shock chamber. The set minimum temperature limit was $-40^{\circ} \mathrm{C}$, and the set maximum temperature limit was $+60^{\circ} \mathrm{C}$, providing a $100^{\circ} \mathrm{C}$ temperature variation range. The specimens were conditioned in each chamber for 15 minutes, not including the time to achieve a stable chamber temperature. Moreover, some of the test specimens were heat-treated by reheating (at $+80^{\circ} \mathrm{C}$ for $2 \mathrm{~h}$ ) to eliminate the effects of high temperature in the thermal shock chamber. Figure 2 shows an overview of the test specimens formed into dumbbells for the determination of the material characteristics before and after the thermal shocks.

Table 1 summarises the pretreatment processes used for the test specimens with the adhesive composition (Epidian 57 with a 10\% Z1 hardener content) used to determine Young's modulus.

The next stage of the tests was to determine the strength of the adhesive, which was done in compliance with the prevailing reference standard. The test specimens were made from grade $316 \mathrm{~L}$ steel, each measuring $25 \times 100 \times 1.5 \mathrm{~mm}$. To develop the geometric surface and remove the physical adsorption layer, the test specimens were mechanically processed with a P320 grit tool for 30 seconds. This mechanical cleaning was done in two steps: first each test specimen was washed with a degreaser (Loctite 7063) followed by wiping with a paper towel (both operations were done twice), and second the test specimens were washed with the degreaser (Loctite 7063) and left for it to evaporate. A PGX goniometer, including software, was used to measure the wetting angle of the grade $316 \mathrm{~L}$ steel surface and determine the SFE (free surface energy). The wetting angle was measured with distilled water and diiodomethane at least ten times on each of the test specimens of interest. The measurements were made on a test panel and followed a level check with an optical level gauge, at an ambient temperature of (19$21)^{\circ} \mathrm{C}$ and $(45-50) \% \mathrm{RH}$. The test liquids used for measuring the wetting angle were applied on the test specimen surface automatically, in drips

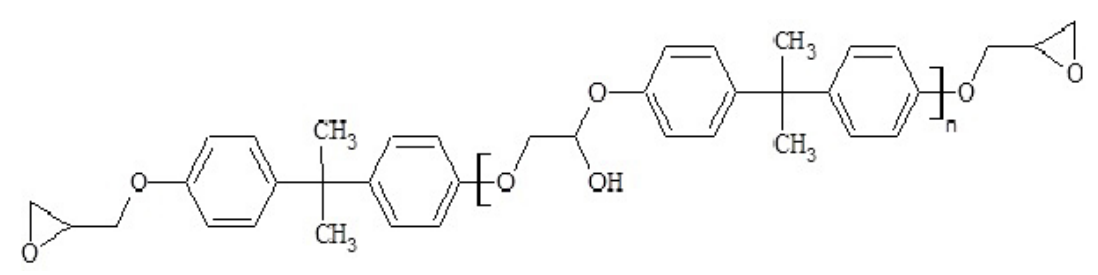

Fig. 1. General formula of the epoxy resin 


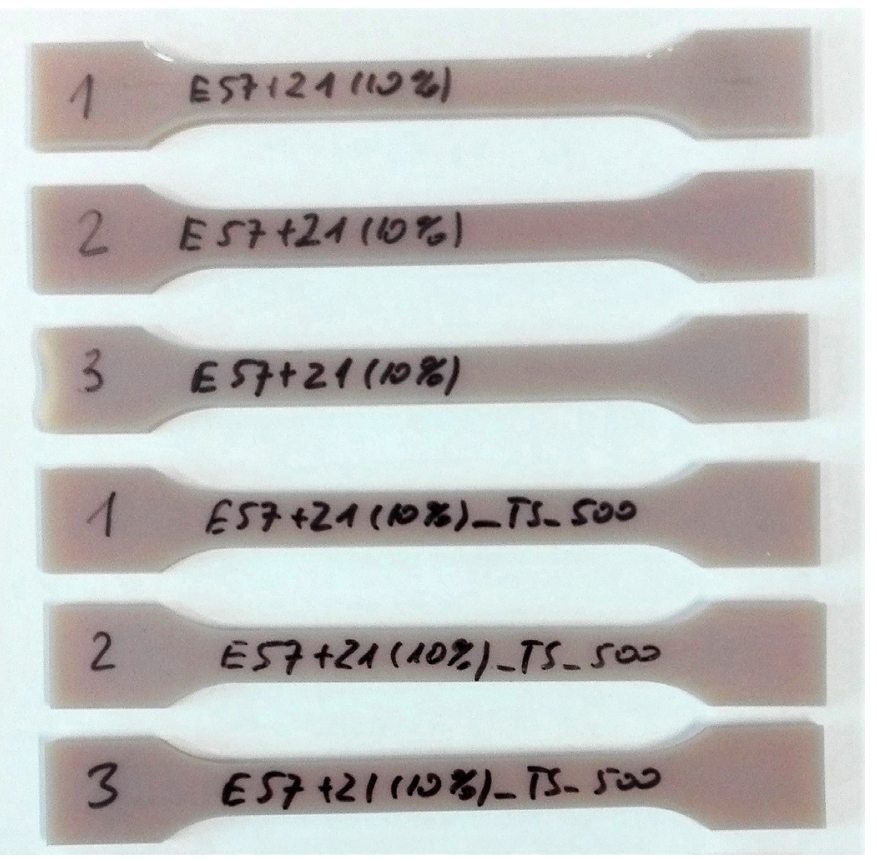

Fig. 2. Overview of the test dumbbells for determination of the material characteristics

Table 1. Pretreatment processes of the test specimens with the composite adhesive (Epidian $57+10 \%$ of $Z 1$ hardener)

\begin{tabular}{|c|l|}
\hline Options & \multicolumn{1}{|c|}{ Pretreatment method for the E57+Z1-10\% specimens } \\
\hline T1 & Specimens prior to thermal shock and reheating treatment \\
\hline T2 & Specimens after 500 cycles of thermal shock treatment, before reheating \\
\hline T3 & Specimens prior to the thermal shock treatment, with reheating at $80^{\circ} \mathrm{C}$ for $2 \mathrm{~h}$ \\
\hline T4 & Specimens after 500 cycles of thermal shock treatment, with reheating at $80^{\circ} \mathrm{C}$ for $2 \mathrm{~h}$ \\
\hline
\end{tabular}

of a constant volume of $5 \mu 1$, as dispensed by the goniometer. For the calculations, the following values of test liquid SFE and their polar and dispersion components were assumed: Water SFE, $\gamma_{\mathrm{w}}=72.8 \mathrm{~mJ} / \mathrm{m}^{2}$; water SFE polar component, $\gamma^{\mathrm{p}}{ }_{\mathrm{w}}$ $=51.0 \mathrm{~mJ} / \mathrm{m}^{2}$; water SFE dispersion component, $\gamma_{\mathrm{w}}^{\mathrm{d}}=21.8 \mathrm{~mJ} / \mathrm{m}^{2}$; diiodomethane SFE, $\gamma_{\mathrm{d}}=50.8$ $\mathrm{mJ} / \mathrm{m}^{2}$; diiodomethane SFE polar component, $\gamma_{{ }_{\mathrm{d}}}^{\mathrm{p}}$ $=2.3 \mathrm{~mJ} / \mathrm{m}^{2}$; diiodomethane SFE dispersion component, $\gamma_{\mathrm{d}}^{\mathrm{d}}=48.5 \mathrm{~mJ} / \mathrm{m}^{2}$.

DSC analysis was performed to determine the glass transition temperature. The cross-linked test specimen was overheated from 0 to $250^{\circ} \mathrm{C}$ at $10^{\circ} \mathrm{C} / \mathrm{min}$, followed by cooling and repeating the overheating. During the tests, the glass transition temperature during the first and second heating was determined.

The test specimens measured $100 \mathrm{~mm}$ x 25 $\mathrm{mm}$ in one plane, each $1.5 \mathrm{~mm}$ thick, of grade 316L steel, and were adhesively bonded to form adhesive joints. Figure 3 shows the schematic layout of the single adhesive lap joint made with the adhesive composition of Epidian 57 and a $10 \% \mathrm{Z} 1$ hardener content. The adhesive layer thickness was $\mathrm{g}_{\mathrm{k}}=0.1 \mathrm{~mm}$, whereas the lap length was $12.5 \mathrm{~mm}$.

The adhesive composition tested was cured at an ambient temperature of $\left(20-22^{\circ} \mathrm{C}\right)$ and (45-55)\% RH. The unit pressure applied to the test specimen surface during the adhesive bonding process was $0.2 \mathrm{MPa}$ and the curing time of the adhesive composition was 120 hours. Some of the single adhesive lap joint test specimens were exposed to thermal load cycles.

Table 2 summarises the test specimen preparation process to produce single adhesive lap joints for grade $316 \mathrm{~L}$ steel bonded with the adhesive composition.

For these tests, a Keyence VHX-5000 microscope was used for image work with the grade 316L steel specimens before and after mechanical preparation with the P320 grit tools.

The surface roughness was measured with a Hommel-Etamic 3D T8000 RC-120-400 tool and a dia. $2 \mu \mathrm{m}$ feeler, while the elementary section length was chosen according to the reference literature [15]. 


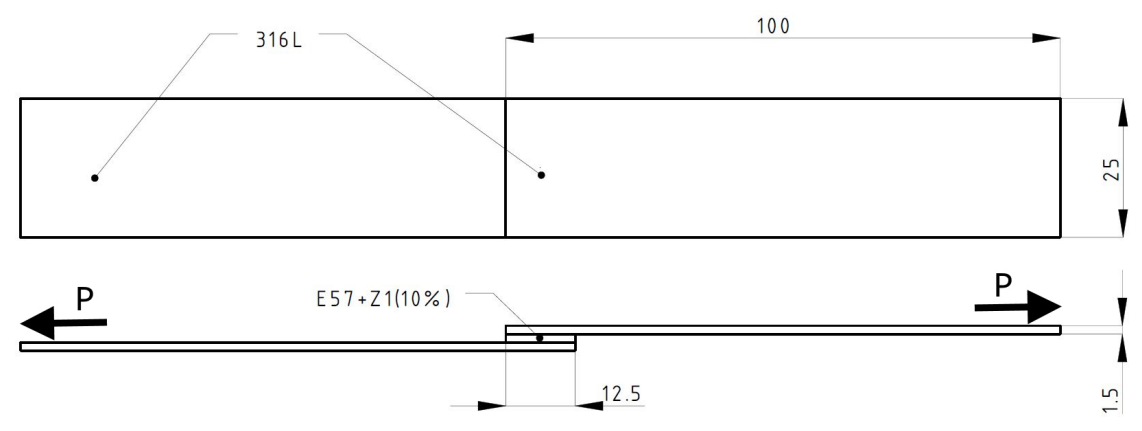

Fig. 3. Schematic of the single adhesive lap joint of grade 316L steel with adhesive composition of Epidian 57 and a 10\% Z1 hardener content

Table 2. Adhesive joint test specimen preparation processes

\begin{tabular}{|c|l|}
\hline Options & \multicolumn{1}{|c|}{ Preparation process for the single adhesive lap joint test specimens } \\
\hline P1 & As-seasoned, without grit surface preparation, without thermal shock cycling \\
\hline P2 & As-seasoned, without grit surface preparation, after 500 thermal shock cycles \\
\hline P3 & As-seasoned, after grit surface preparation, without thermal shock cycling \\
\hline P4 & As-seasoned, after grit surface preparation, after 500 thermal shock cycles \\
\hline
\end{tabular}

The strength tests intended to determine the Young's modulus of the adhesive composition test specimens conformed to the method established in DIN EN ISO 527-1, whereas the shear tests on the single adhesive lap joints conformed to the method established in DIN EN 1465. The destructive testing was performed using a Zwick/ Roell Z150 strength testing machine.

\section{RESULTS AND DISCUSSION}

\section{Analysis of selected surface roughness parameters}

Table 3 is a summary of the $3 \mathrm{D}$ isometric maps of the test specimens before and after mechanical preparation with the P320 grit tool and includes 2D profiles. The marks shown by the surface topography maps are typical of this type of surface preparation.

Table 4 lists the selected 3D surface roughness parameters for all the studied options of the test specimens. The following 3D parameters were considered: $\mathrm{Sq}$ - root mean square value of the 3D profile datums; $\mathrm{Sp}$ - maximum 3D profile peak height; $\mathrm{Sv}$ - minimum 3D profile valley depth; $\mathrm{Sz}$ - maximum 3D profile height; $\mathrm{Sa}$ - arithmetic mean of the 3D profile datums. Before the measurements, the surfaces of the test specimens were cleaned and degreased with Loctite 7063. Note that the surface roughness profile indicates that the grit tool mechanical preparation effectively developed the required surface finish and removed contaminants from the superficial layer.

The tests indicate an unambiguous increase in all surface roughness parameters for all grade $316 \mathrm{~L}$ steel specimens following the surface preparation with the P320 grit tool in comparison to the condition of test specimens prior to the mechanical preparation.

\section{Test specimen surface imaging}

Figure 4 shows the photographic imaging of the grade $316 \mathrm{~L}$ steel specimens before and after surface preparation with the P320 grit tool.

The photographs were taken with a 500x magnification. Figure 4(b) shows the characteristics scratches due to the kinematics of the mechanical preparation process and the nature of the grit tool. The surface preparation with the grit tool was intended to remove the layer of contaminants, or the physical adsorption layer.

\section{Surface free energy}

Table lists the mean values of surface free energy (SFE) for grade 316L steel before and after the surface preparation with the P320 grit tool, including the calculated standard deviation. The table also lists the SFE polar and the SFE dispersion component. 
Table 3. 3D isometric maps of the test specimens before and after the surface preparation with the P320 grit tool, with 2D profiles

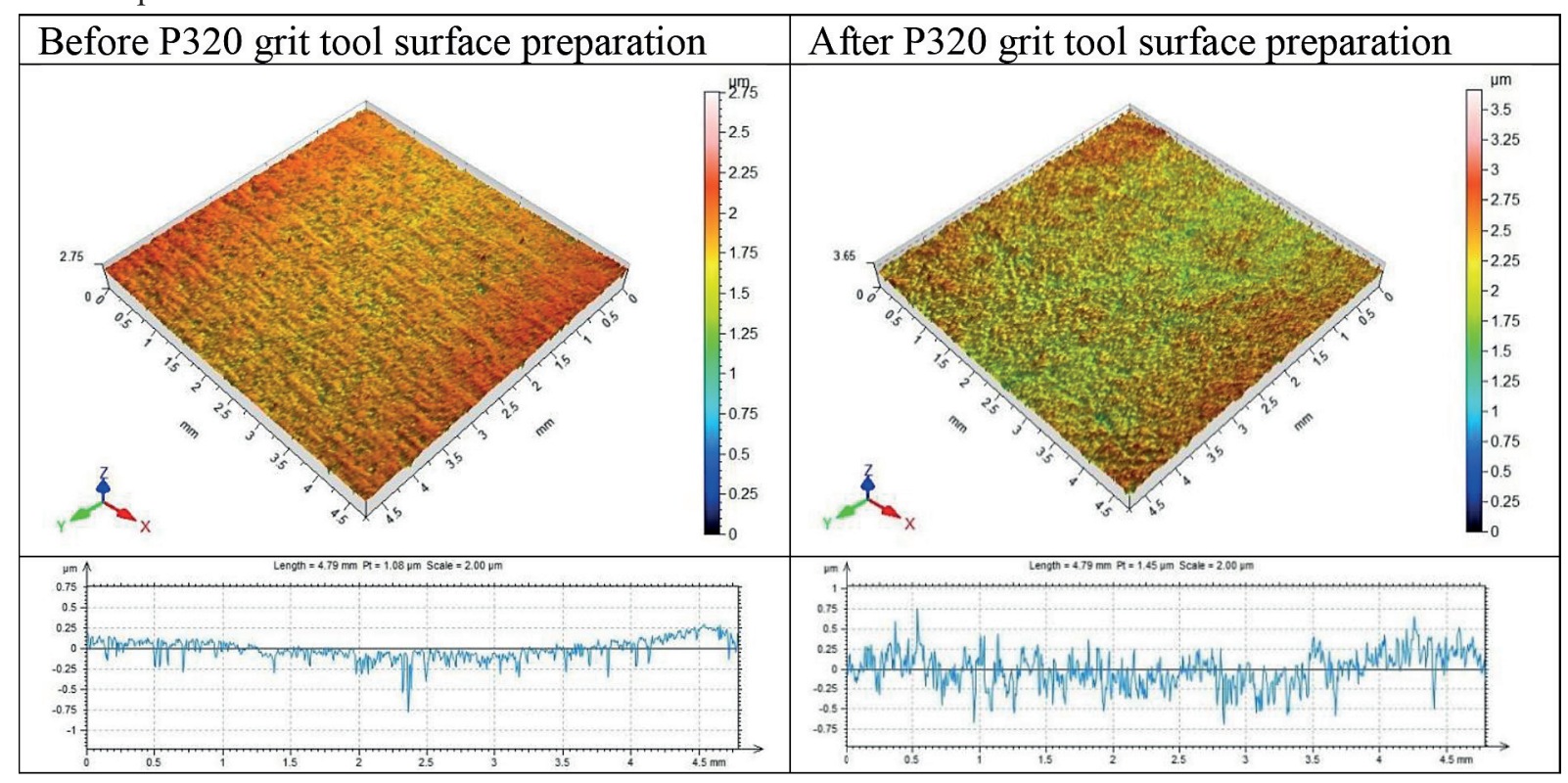

Table 4. 3D surface roughness parameters of grade $316 \mathrm{~L}$ steel

\begin{tabular}{|l|c|c|c|c|c|}
\hline \multirow{2}{*}{ Option } & \multicolumn{5}{|c|}{ 3D parameters [um] } \\
\cline { 2 - 6 } & $\mathrm{Sq}$ & $\mathrm{Sp}$ & $\mathrm{Sv}$ & $\mathrm{Sz}$ & $\mathrm{Sa}$ \\
\hline $\begin{array}{l}\text { Pre-P320 grit tool surface } \\
\text { preparation }\end{array}$ & 0.126 & 0.868 & 1.88 & 2.78 & 0.0918 \\
\hline $\begin{array}{l}\text { Post-P320 grit tool surface } \\
\text { preparation }\end{array}$ & 0.232 & 1.44 & 2.25 & 3.69 & 0.182 \\
\hline
\end{tabular}

Table 5. SFE and its components in grade $316 \mathrm{~L}$ steel

\begin{tabular}{|l|c|c|c|}
\hline \multicolumn{1}{|c|}{ Parameters } & SFE $\left[\mathrm{mJ} / \mathrm{m}^{2}\right]$ & SFE polar component $\left[\mathrm{mJ} / \mathrm{m}^{2}\right]$ & SFE dispersion component $\left[\mathrm{mJ} / \mathrm{m}^{2}\right]$ \\
\hline \multicolumn{5}{|c|}{ Grade $316 \mathrm{~L}$ steel before surface preparation } \\
\hline Mean & 50.6 & 6.2 & 44.4 \\
\hline Standard deviation & 1.3 & 1.2 & 1.3 \\
\hline \multicolumn{5}{|c|}{ Grade 316L steel after surface preparation } \\
\hline Mean & 62.1 & 15.4 & 46.7 \\
\hline Standard deviation & 1.6 & 1.4 & 1.2 \\
\hline
\end{tabular}

a)

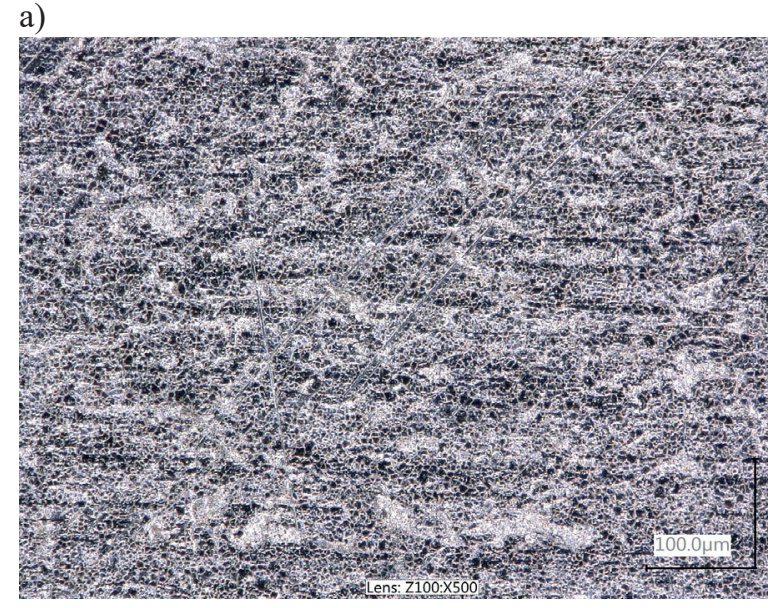

b)

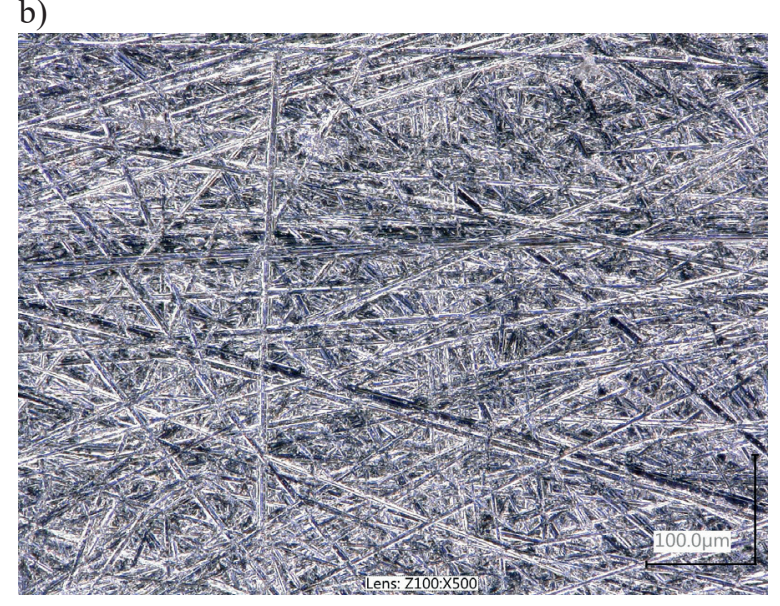

Fig. 4. Photographic imaging of the grade 316L steel specimens: (a) before P320 grit tool surface preparation; (b) after P320 grit tool surface preparation 
The tests were performed on the SFE to verify the correct pretreatment of the grade 316L steel superficial layer for application of the adhesive processes, including the adhesive bonding. The tests revealed a small scatter in the results both for the test specimens before and after the surface preparation with the P320 grit tool, which could mean that the energy state was homogeneous over the surfaces of the adhesively bonded specimens. This energy state favours the production of adhesive joints. This analysis revealed an unambiguous increase in SFE for all grade $316 \mathrm{~L}$ steel specimens following the surface preparation with the P320 grit tool in comparison to the condition of test specimens prior to the surface preparation. The SFE increased by $18.5 \%$ and is advantageous in adhesive technologies. Energetic properties of constructional materials surface layer are very important features in adhesive bonds constructions. These connections are for example: contact bonding, sealing, varnishing, etc. The parameter that determines the effectiveness of joining the surfaces of construction materials is the adhesive energy, which is the work necessary to separate the two layers of the adhesive joints material without penetrating the nature of the interactions causing the formation of a permanent joint.

\section{Glass transition temperature}

In this test carried out on the test specimens produced with the $\mathrm{T} 1$ process, the determination of the glass transition temperature proved to be difficult as the test specimen underwent curing, which should begin at $60^{\circ} \mathrm{C}$ in the test setup. The curing enthalpy had the exothermic peak shown in red in Figure 5.

The test specimen (T1) was heated at a rate of $10^{\circ} \mathrm{C} / \mathrm{min}$, and the cross-linking process enthalpy shown in Figure 6 was $368 \mathrm{~J} / \mathrm{g}$. Naturally, the process was exothermic, which meant it produced heat (see the peak pointing upward). The cross-linked test specimen was overheated from 0 to $250^{\circ} \mathrm{C}$ at $10^{\circ} \mathrm{C} / \mathrm{min}$, followed by cooling and repeating the overheating (Figure 7). The glass transition temperature of the cured adhesive composition was $79^{\circ} \mathrm{C}$ and reached $85^{\circ} \mathrm{C}$ in the second heating run, exceeding the first run by 6 degrees. This meant that the crosslinked test specimen was fully cross-linked in the first $0-250^{\circ} \mathrm{C}$ heating run.

For the test specimens prepared in the T3 process, which included reheating at $80^{\circ} \mathrm{C}$ for 2 hours, three tests were performed to determine the glass transition temperature. An example of the glass transition temperature determination on a $\mathrm{T} 3$ process test specimen is the trend shown in Figure 8, while a summary of all the test results is given in Figure 9.

The tests led to a conclusion that the T1 process test specimen was not cured fully, whereas all the three test specimens produced with the T3 process were fully cured. Naturally, the glass transition temperature in the second heating run was higher than in the first heating run, because the test specimens were always fully cured in the first overheating run within $0-200^{\circ} \mathrm{C}$. For the T3 process test specimens, the glass transition temperatures were, respectively: test specimen \#1 (first heating run, glass transition

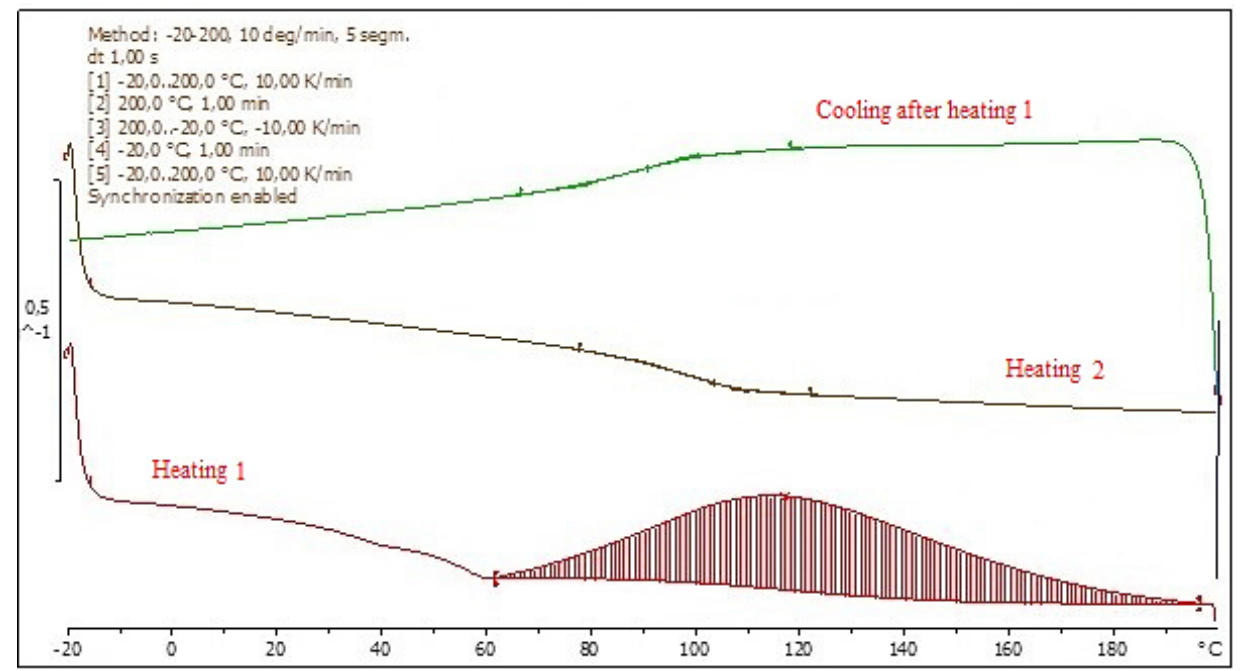

Fig. 5. Determination of the glass transition temperature in the $\mathrm{T} 1$ process test specimen 


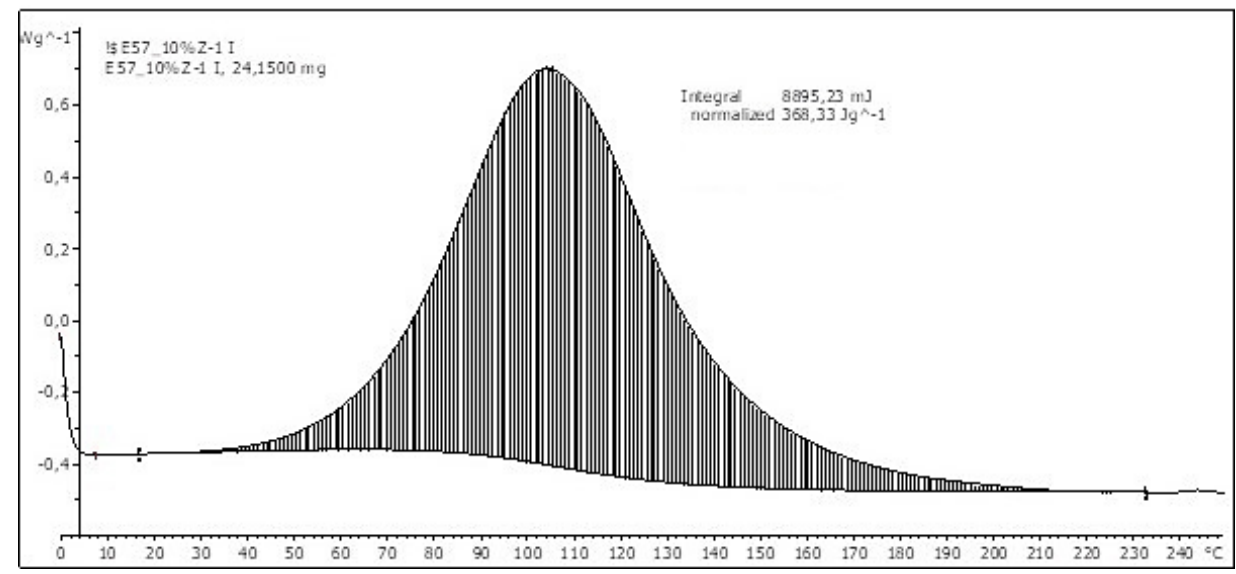

Fig. 6. Curing enthalpy of the $\mathrm{T} 1$ process test specimen

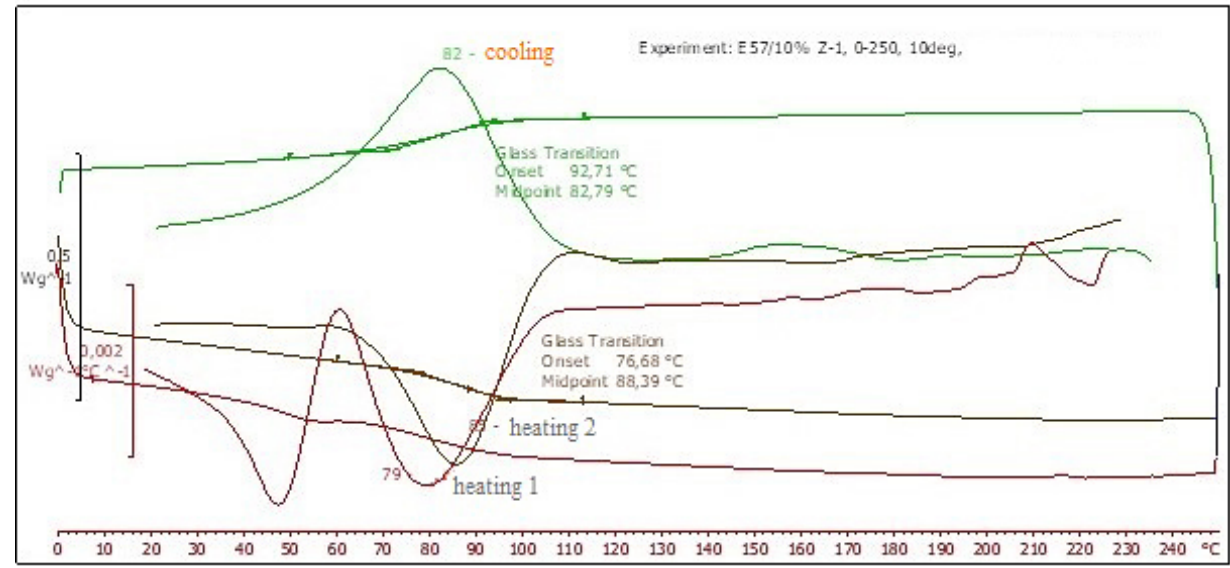

Fig. 7. Heating of the $\mathrm{T} 1$ process test specimen within $0-250^{\circ} \mathrm{C}$

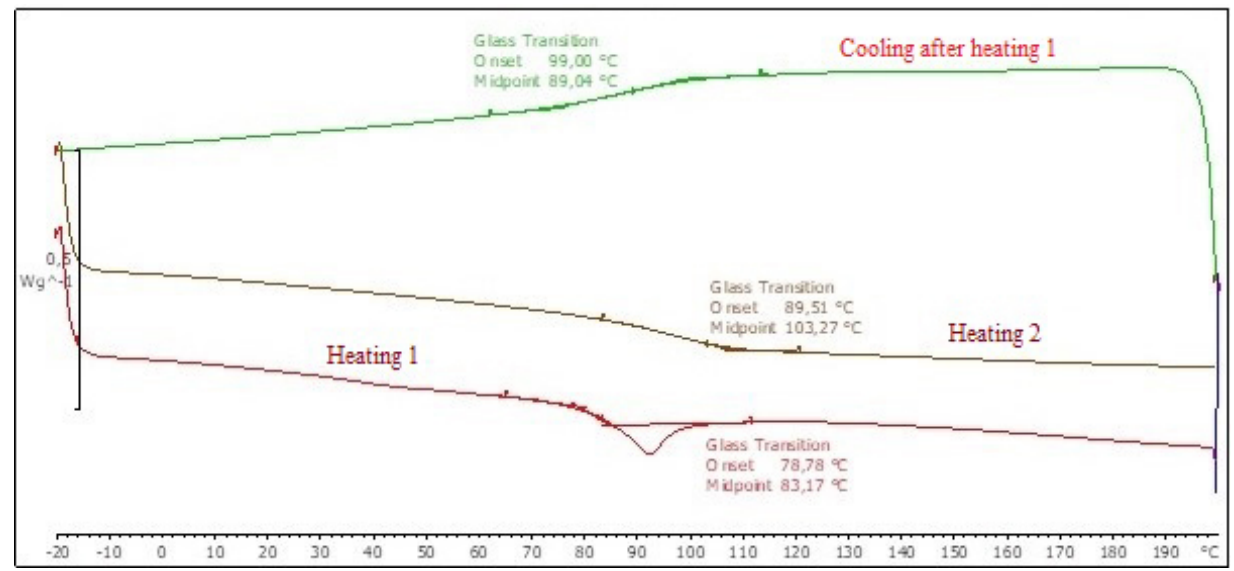

Fig. 8. An example of the glass transition temperature determination for a T3 process test specimen

temperature $-91^{\circ} \mathrm{C}$; second heating run, glass transition temperature $-103^{\circ} \mathrm{C}$ ); test specimen \#2 (first heating run, glass transition temperature $-93^{\circ} \mathrm{C}$; second heating run, glass transition temperature $-104^{\circ} \mathrm{C}$ ); test specimen \#3 (first heating run, glass transition temperature $93^{\circ} \mathrm{C}$; second heating run, glass transition temperature $-100^{\circ} \mathrm{C}$ ).

\section{Young's modulus of the adhesive composition (E57+Z1-10\%)}

Figures 10 to 13 show the trends of stress based on which the Young's modulus values were determined for the adhesive composition of Epidian 57 with a 10\% Z1 hardener content. The test specimens for the Young's modulus 


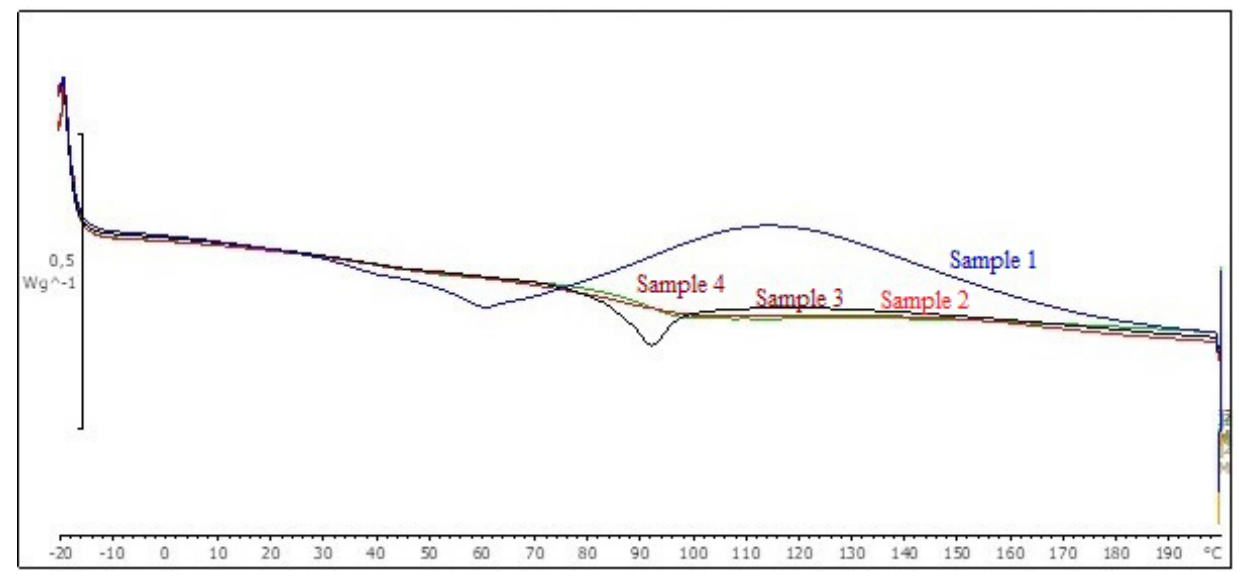

Fig. 9. List of test results for the $\mathrm{T} 1$ and $\mathrm{T} 3$ process test specimens

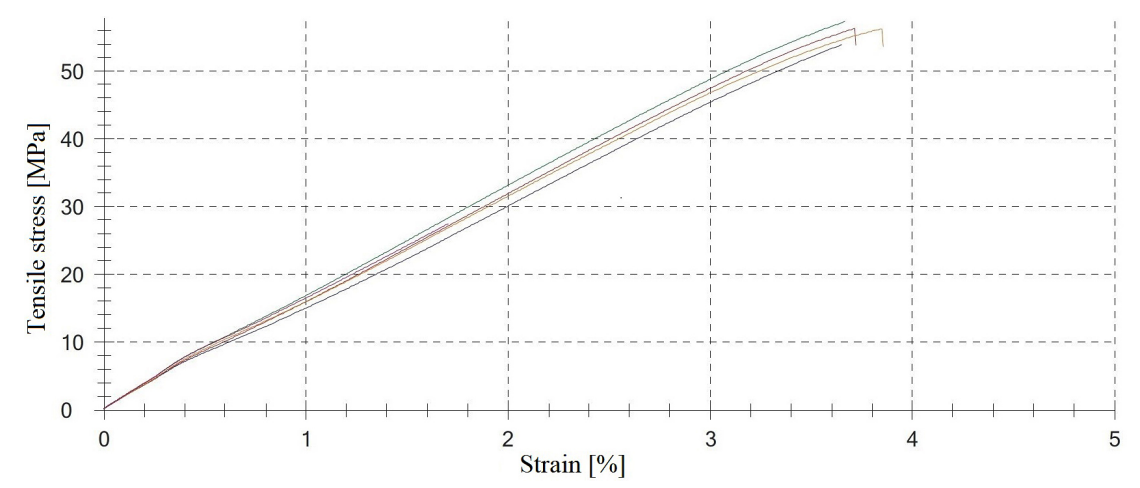

Fig. 10. Young's modulus determination for $\mathrm{T} 1$ process test specimens

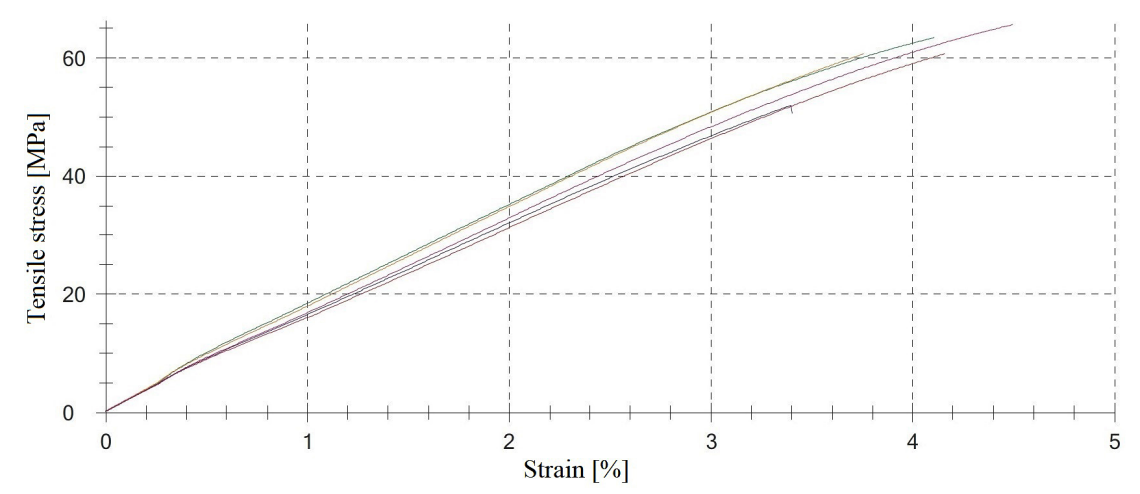

Fig. 11. Young's modulus determination for T2 process test specimens

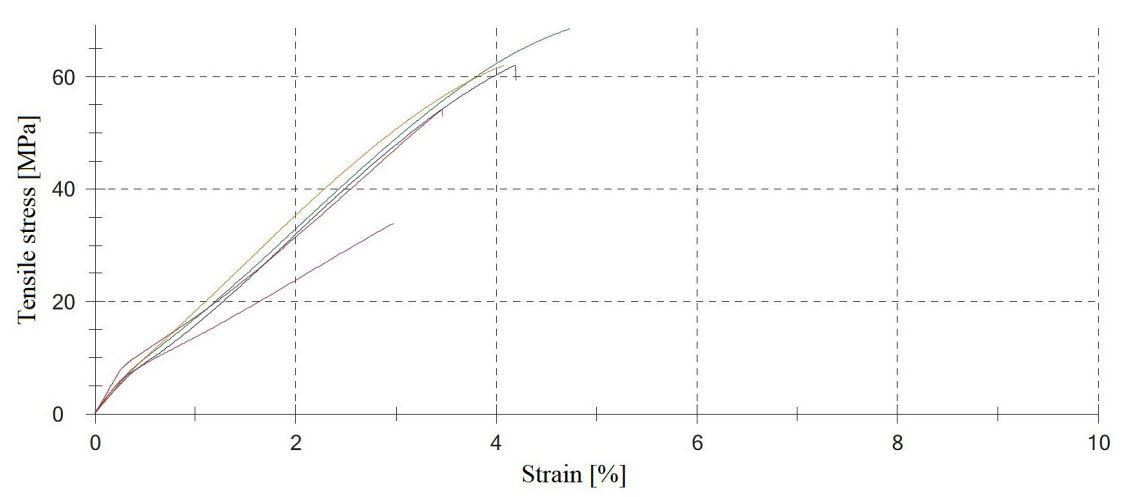

Fig. 12. Young's modulus determination for $\mathrm{T} 3$ process test specimens 


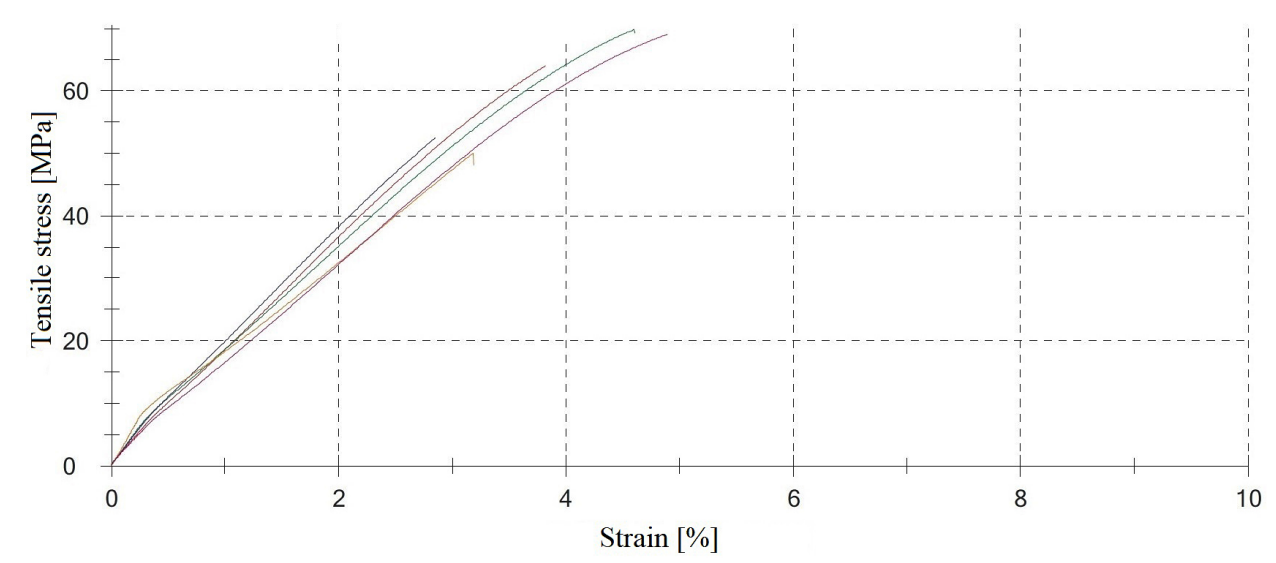

Fig. 13. Young's modulus determination for T4 process test specimens

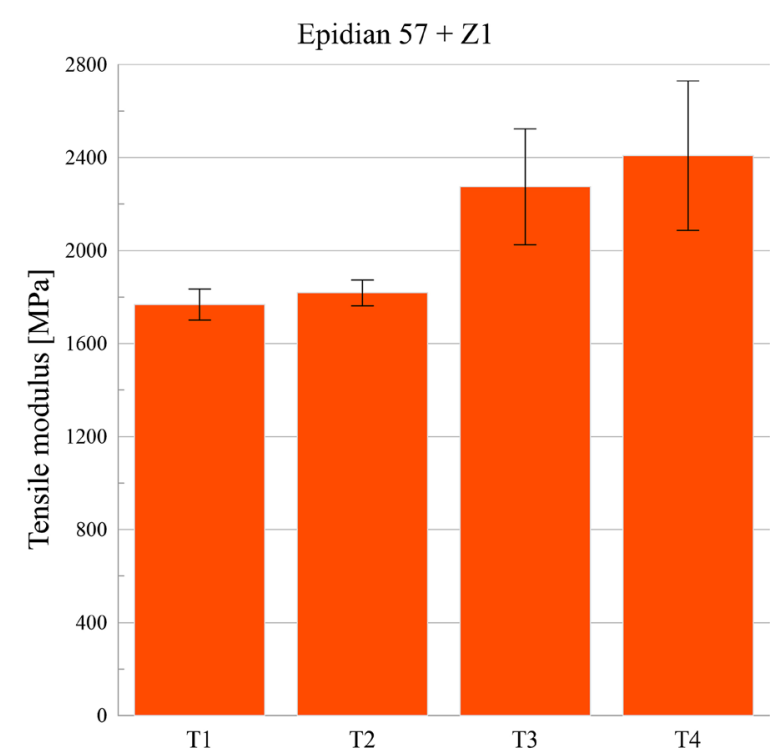

Fig. 14. Young's modulus values for the adhesive composition

determination were pretreated under the conditions listed in Table 1. For each process option, five test specimens of the material were produced, and the mean values are shown in Figure 14 with the measure of scatter.

The tests performed on the adhesive composition (Epidian $57+10 \%$ of Z1 hardener) revealed an increase in Young's modulus following the reheating run at $80^{\circ} \mathrm{C}$ for $2 \mathrm{~h}$ in comparison to the test specimens before the reheating run. The highest increase (36\%) was found for the T4 process test specimens compared to the $\mathrm{T} 1$ process test specimens. For the test specimens prior to thermal shock cycling, i.e. the T1 and T3 processes, Young's modulus increased by $29 \%$ for the T3 process test specimens compared to the T1 process test specimens. A significant increase in scatter around the mean value was found for the test specimens following the reheating run ( $\mathrm{T} 3$ and $\mathrm{T} 4$ processes) compared to the test specimens before the reheating run (T1 and T2 processes). The measure of scatter was the standard deviation which increased five-fold in this case.

\section{Adhesive joint strength}

Figures 15 to 18 show the failure stress trends in the single adhesive joint specimens prepared in the process shown in Table 2. The processing of the test specimens for this test included surface preparation of grade $316 \mathrm{~L}$ steel with the P320 grit tool and loading with variable thermal stress. For each process option, 10 test specimens were produced.

An analysis of the failure stress trends in the single adhesive lap joints revealed larger scatters in the trends for the post-thermal-shock cycled specimens ( $\mathrm{P} 2$ and $\mathrm{P} 4)$ than in the test specimens before the thermal shock cycling (P1 and P3). Figure 19 shows the mean values of strength for the single adhesive lap joints from the function of the test specimen process option, plus the standard deviation values.

The tests revealed a reduction of the failure stress values in the single adhesive lap joints after the thermal shock cycling in comparison to the test specimens before the thermal shock cycling. This reduction occurred for the test specimens with and without surface preparation with the P320 grit tool. For the test specimens before the surface preparation, the failure stress was reduced by $20 \%$ for the post-thermal-shock cycled specimens compared to the specimens before the thermal shock cycling. For the test specimens with surface preparation with the P320 grit tool, the failure stress was reduced more, by $45 \%$ 


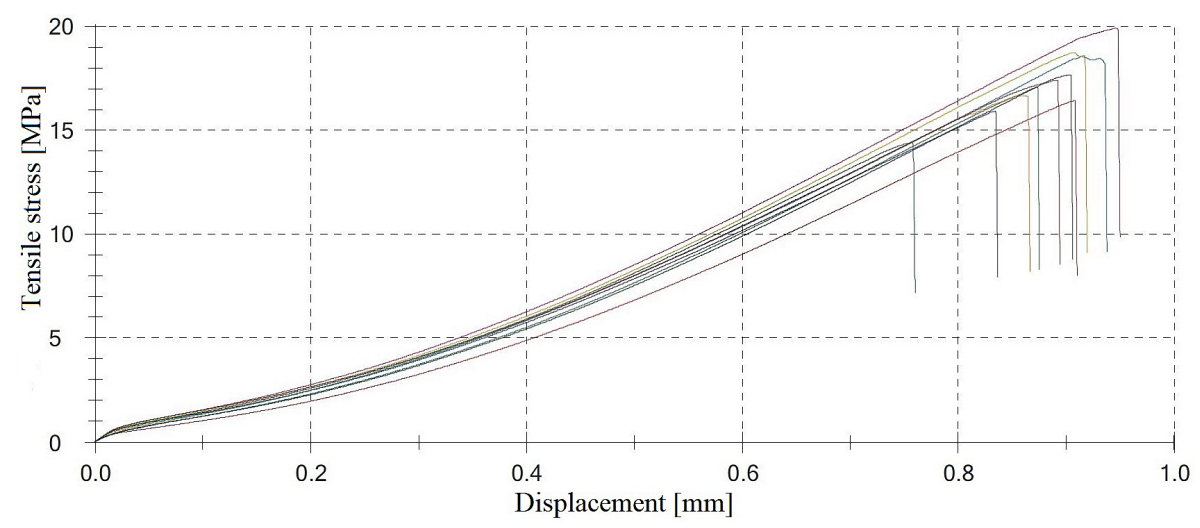

Fig. 15. Failure stress trends for the $\mathrm{P} 1$ processing of single adhesive joint specimens

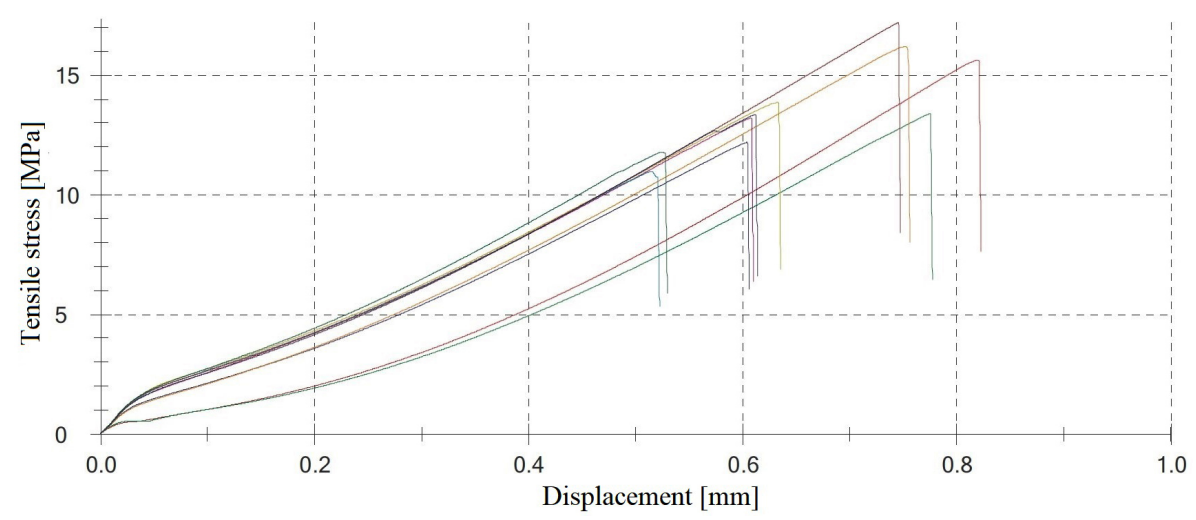

Fig. 16. Failure stress trends for the $P 2$ processing of single adhesive joint specimens

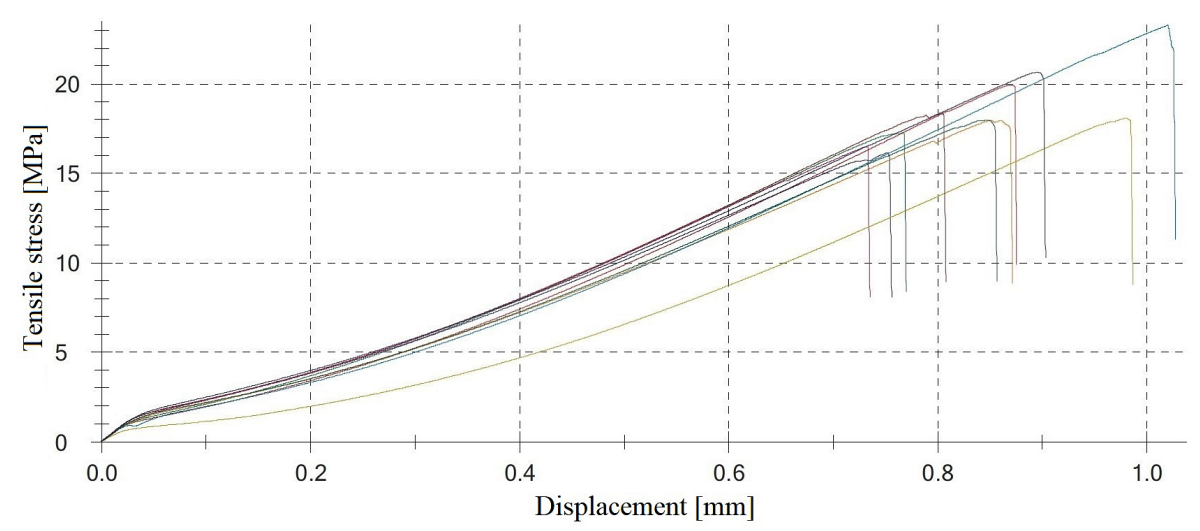

Fig. 17. Failure stress trends for the $\mathrm{P} 3$ processing of single adhesive joint specimens

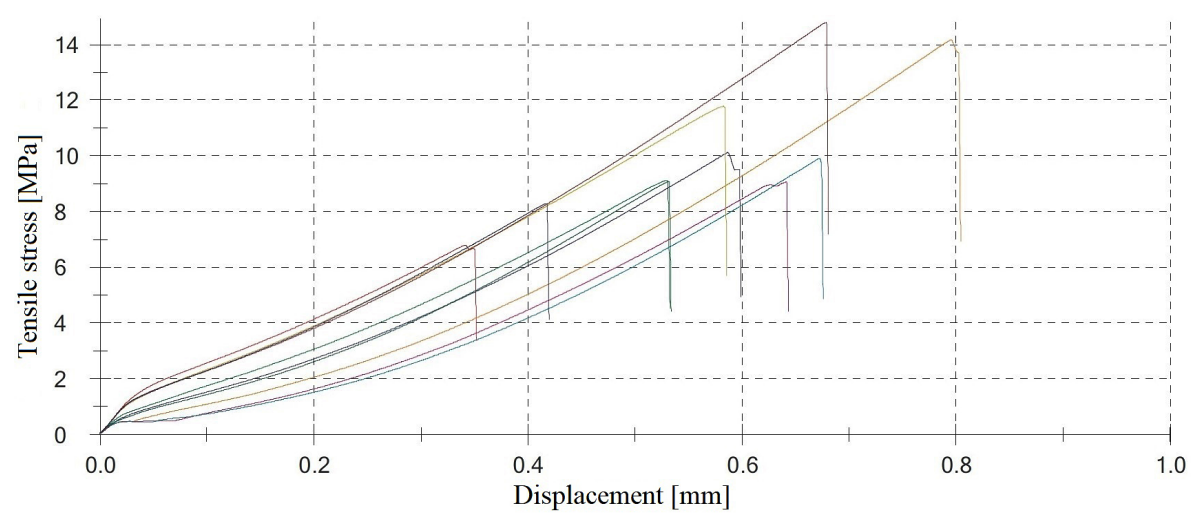

Fig. 18. Failure stress trends for the $\mathrm{P} 4$ processing of single adhesive joint specimens 


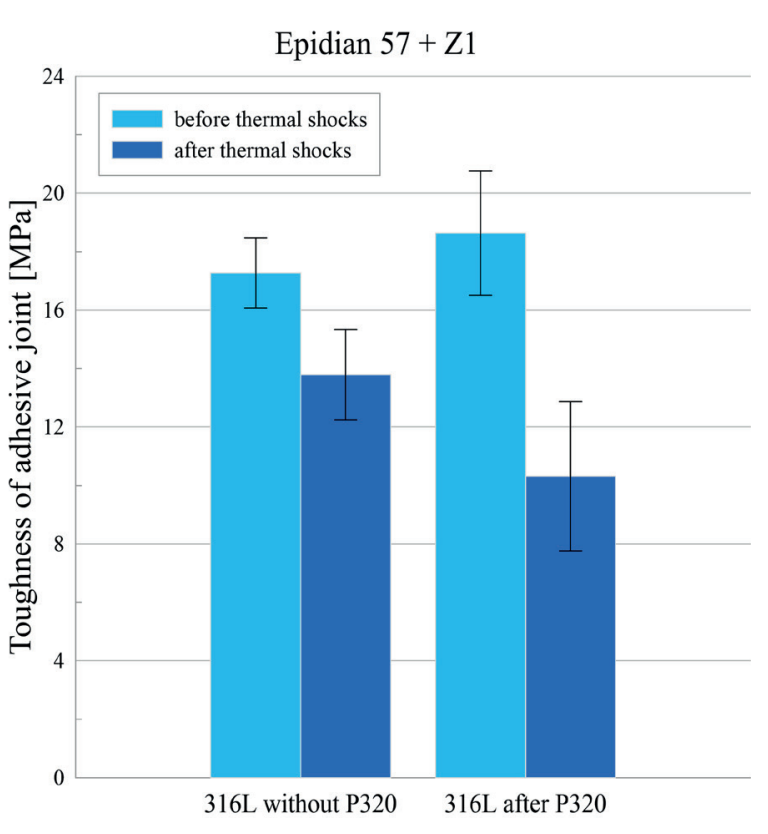

Fig. 19. Adhesive joint strength vs. specimen process option for the post-thermal-shock cycled specimens compared to the specimens before the thermal shock cycling.

\section{Imaging of the test specimens after the strength tests}

Table 5 shows the photographic imaging of the test specimens after the strength tests. The photographs show the test specimens before and after the surface preparation with the P320 grit tool and before and after the 500 cycles of thermal shock treatment. The photographs were taken with a 500x magnification.

The photographs revealed the adhesivecohesive nature of the specimen fractures, especially in those with surface preparation by the P320 grit tool and after the thermal shock cycling. This could be evidence of thermal fatigue of the tested single adhesive lap joints.

Table 5. Imaging of the test specimens after the strength tests

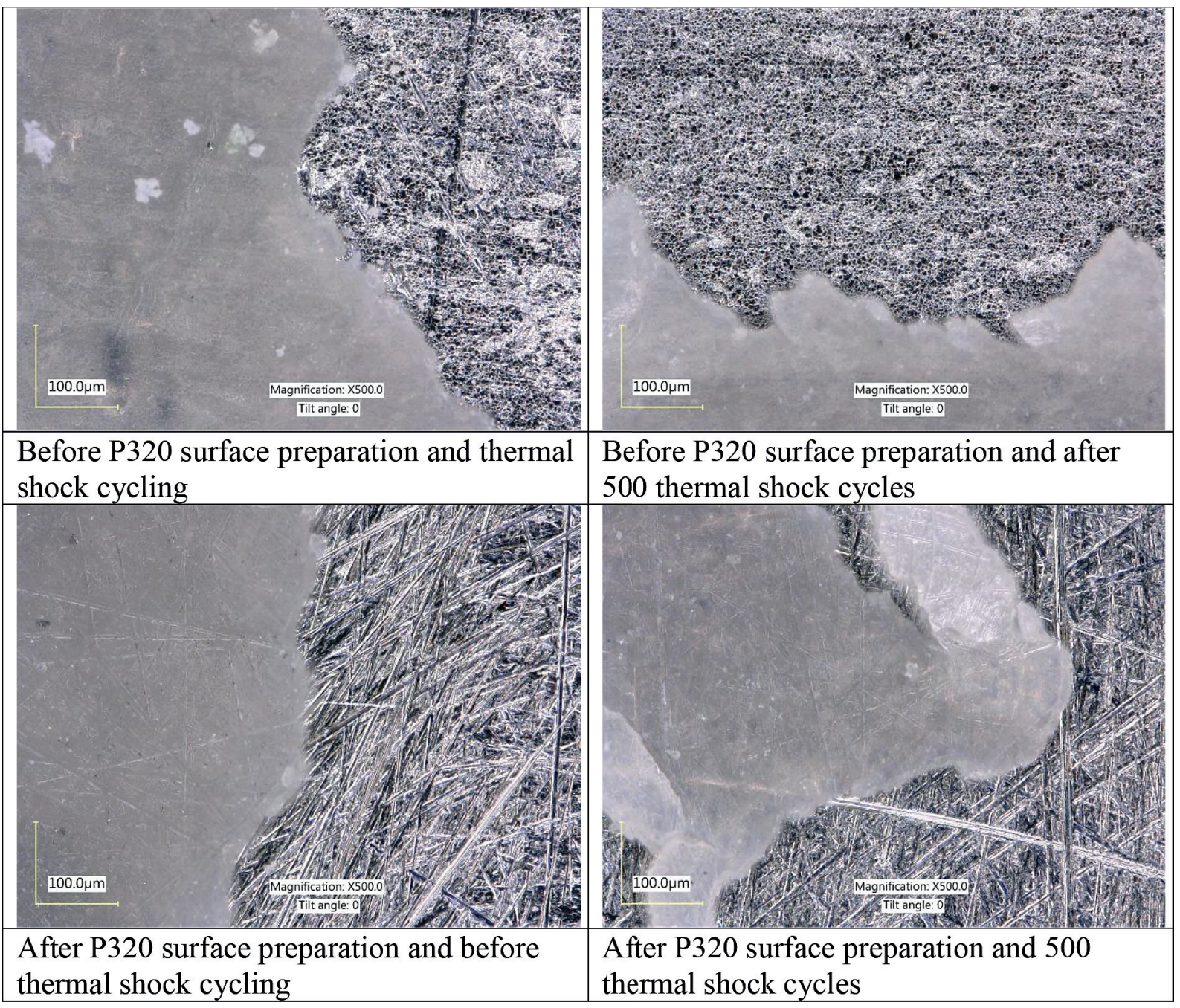




\section{CONCLUSIONS}

The following conclusions can be drawn from the tests and the test result analysis discussed in this work:

1. An unambiguous increase in all surface roughness parameters was found for all grade $316 \mathrm{~L}$ steel specimens following the surface preparation with the P320 grit tool in comparison to the condition of test specimens prior to the surface preparation. Sz, the surface roughness, increased by $32 \%$.

2. The SFE increased with the grade $316 \mathrm{~L}$ steel by approximately $23 \%$ after the surface preparation in comparison to the condition prior to the surface preparation.

3. The glass transition temperature tests revealed that the T1 process test specimens were not cured fully. The reheating of the test specimens caused full cross-linking and increased the glass transition temperature by $17 \%$.

4. The tests performed on the adhesive composition (Epidian $57+10 \%$ of $\mathrm{Z} 1$ hardener) revealed an increase in Young's modulus following the reheating at $80^{\circ} \mathrm{C}$ for $2 \mathrm{~h}$ in comparison to the test specimens before reheating. The highest increase (36\%) was found for the $\mathrm{T} 4$ process test specimens compared to the $\mathrm{T} 1$ process test specimens.

5. The tests revealed a reduction in the failure stress values for the single adhesive lap joints after the thermal shock cycling in comparison to the test specimens before the thermal shock cycling. The highest reduction was found for the test specimens after the surface preparation with the P320 grit tool and amounted to $45 \%$ for the post-thermal-shock cycled specimens compared to the test specimens before the thermal shock cycling.

\section{REFERENCES}

1. Godzimirski J. Problemy klejenia konstrukcyjnego. Technologia i Automatyzacja Montażu. 2009; 1: $25-31$.

2. Kłonica M., Kuczmaszewski J., Samborski S. Effect of a Notch on Impact Resistance of the Epidian 57/Z1 Epoxy Material after "Thermal Shock". Solid State Phenom. 2016; 240: 161-167. https:// doi:10.4028/www.scientific.net/SSP.240.161.

3. Kuczmaszewski J. Fundamentals of metal-metal adhesive joint design. Politechnika Lubelska, Oddział PAN w Lublinie, Lublin; 2006.

4. Mogilski M., Jabłoński M., Deroszewska M., Sar- aczyn R., Tracz J., Kowalik M., Rządkowski W. Investigation of Energy Absorbed by Composite Panels with Honeycomb Aluminum Alloy Core. Materials. 2020; 13: 5807. https://doi.org/10.3390/ ma13245807.

5. Kłonica M. Impact of Thermal Fatigue on Young's Modulus of Epoxy Adhesives. Advances in Science and Technology Research Journal. 2015; 9: 103106. https://10.12913/22998624/60795.

6. Kubit A., Trzepiecinski T., Kłonica M., Hebda M., Pytel M. The influence of temperature gradient thermal shock cycles on the interlaminar shear strength of fibre metal laminate composite determined by the short beam test. Compos B Eng. 2019; 176: 107217. https://doi.org/10.1016/j.compositesb.2019.107217.

7. Surowska B., Dadej K., Jakubczak P., Bieniaś J. Short-beam shear fatigue life assessment of thermally cycled carbon-aluminium laminates with protective glass interlayers. Archives of Civil and Mechanical Engineering. 2021; 21(2): 1-11. https://doi.org/10.1007/s43452-021-00181-y.

8. Skoczylas J., Samborski S., Kłonica M. A Multilateral Study on the FRP Composite's Matrix Strength and Damage Growth Resistance. Compos. Struct. 2021; 263: 113752. https://doi.org/10.1016/j.compstruct.2021.113752.

9. Humfeld G.R.J. Mechanical behavior of adhesive joints subjected to thermal cycling. Virginia Polytechnic Institute, Blacksburg, Virginia; 1997.

10. Bielawski R., Rządkowski W., Kowalik M.P., Kłonica M. Safety of Aircraft Structures in the Context of Composite Element Connection. Int Rev Aerospace Eng (IREASE). 2020; 13(5): 159164. https://doi.org/10.15866/irease.v13i5.18805.

11. Rządkowski W., Tracz J., Cisowski A., Gardyjas K., Groen H., Palka M., Kowalik M. Evaluation of Bonding Gap Control Methods for an Epoxy Adhesive Joint of Carbon Fiber Tubes and Aluminum Alloy Inserts. Materials. 2021; 14 1977. https://doi. org/10.3390/ma14081977.

12. Sadowski T., Balawender T., Śliwa R., Golewski P., Kneć M. Modern hybrid joints in aerospace: modeling and testing. Archives of Metallurgy and Materials. 2013; 58(1), 163-169. https://doi.org/10.2478/ v10172-012-0168-3.

13. Sawa M., Szala M., Henzler W. Innovative device for tensile strength testing of welded joints: $3 \mathrm{~d}$ modelling, FEM simulation and experimental validation of test rig - a case study. Appl Comput Sci. 2021; 17: 92-105. https://doi.org/10.23743/acs-2021-24.

14. Kowal M., Szala M. Diagnosis of the microstructural and mechanical properties of over century-old steel railway bridge components. Eng Fail Anal. 2020; 110: 104447. https://doi.org/10.1016/j.engfailanal.2020.104447.

15. Humienny Z. Specyfikacje Geometrii Wyrobów (GPS) - Wykład dla Uczelni Technicznych. Oficyna wydawnicza PW; 2001. 